\title{
Conf-911109--2
}

\section{OBSIDIANS AND TEKTITES: NATURAL ANALOGUES FOR WATER DIFFUSION IN NUCLEAR WASTE GLASSES*}

ANL/CP--73431

DE92 001923

James J. Mazer, ${ }^{1}$ John K. Bates, 1

Christopher M. Stevenson, ${ }^{2}$ and Charles R. Bradley 1

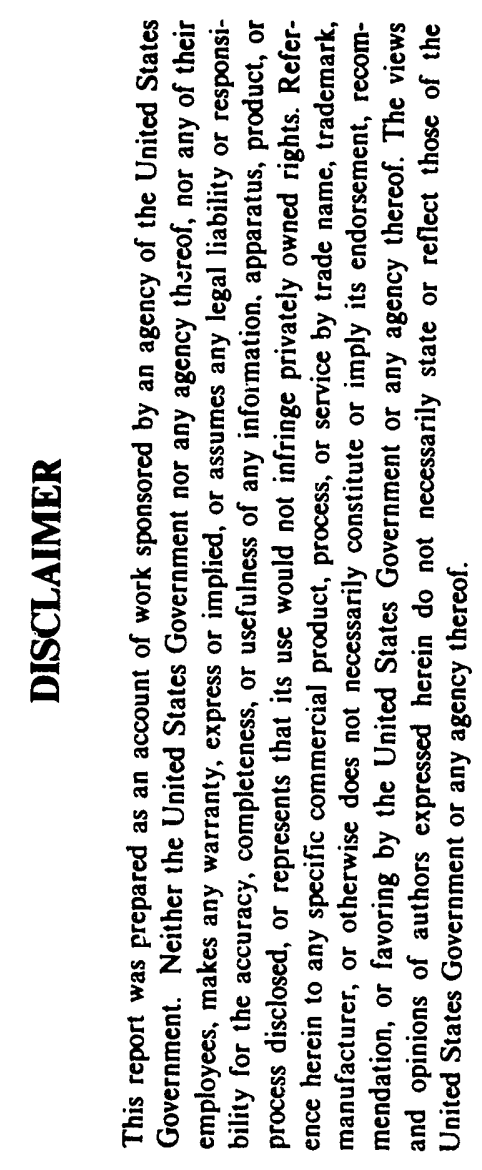

1Chemical Technology Division

\author{
Argonne National Laboratory \\ Argonne, IL 60439
}

2 Archaeological Services Consultants

P. O. Box 02095

Columbus, $\mathrm{OH} 42302$

\begin{abstract}
The submitted manuscript has been authored by a contractor of the U.S. Government by a contractor of the W.31-109ENG-38. under contract $U$. S. Government retains a Accordingly, the U.S. Government retains a

nonexclusive, royalty-free license to publish

or reproduce the published form of this

contribution, or allow others
\end{abstract}

$$
\text { Submitted to }
$$

Fall 1991 Materials Research Society Meeting Scientific Basis for Nuclear Waste Management XV Strasbourg, France

November 4-7, 1991

\footnotetext{
"Work supported by the U.S. Department of Energy, Office of Environmental Restoration and Waste Management, under Contract W-31-109-ENG-38.
} 


\title{
OBSIDIANS AND TEKTITES: NATURAL ANALOGUES FOR WATER DIFFUSION IN NUCLEAR WASTE GLASSES
}

\author{
JAMES J. MAZER, ${ }^{1}$ JOHN K. BATES, ${ }^{1}$ CHRISTOPHER M. STEVENSON, ${ }^{2}$ AND \\ C. R. BRADLEY 1 \\ ${ }^{1}$ Chemical Technology Division, Argonne National Laboratory, Argonne, IL 60439 \\ ${ }^{2}$ Archaeological Services Consultants, P. O. Box 02095, Columbus, OH 42302
}

\section{INTRODUCTION}

Nuclear waste glasses have been shown to react with water via a number of reaction processes including molecular water diffusion, ion exchange, surface reaction (etching) and secondary mineral formation. The interactions between the processes are significantly affected by such reaction variables as glass composition, solution composition, reaction temperature and reaction time so that separating the competing effects of each process complicates the development of an understanding of the reaction mechanism. Understanding how each individual process behaves in similar glass systems can assist in elucidating nuclear waste glass reactions mechanisms.

Our method of relating natural analogues to the reaction of water with nuclear waste glasses is accomplished through a detailed experimental study of the reaction mechanisms. The initial step is to develop a means of experimentally altering natural samples via the same reaction mechanism encountered in nature. This is usually performed at reaction accelerating conditions so it is crucial to establish that the reaction mechanisms are not aifected by the acceleration techniques. Once experimental techniques for altering natural samples are in place, then the nuclear waste glasses are experimentally altered, using the same techniques. Detailed surface characterizations are performed on the nuclear waste glasses. If it can be shown that identical reaction mechanisms are found in natural samples, experimentally altered natural samples and experimentally altered nuclear waste glasses, then there is a basis for extrapolating the long-term performance of the nuclear waste glass, based on the natural analogues. If the reaction mechanisms differ, the information gained from studies of natural analogs may still be useful in interpreting nuclear waste glass reaction mechanisms because of their long-term nature.

Projected scenarios for the proposed Yucca Miountain repository include significant periods of time when high relative numidity atmospheres will be present, thus the reaction processes of interest will include those known to occur under these conditions. The ideal natural analog for the proposed Yucca Mountain repository would consist of natural borosilicate glasses exposed to expected repository conditions for thousands of years; however, the prospects for identifying such an analog are remote, but an important caveat for using natural analog studies is to relate the reaction processes in the analog to those in the system of interest, rather than a strict comparison of the glass compositions. In lieu of this, identifying natural glasses that have reacted via reaction processes expected in the repository is the most attractive option.

It has been shown that the reaction mechanism for natural obsidian and tektite glasses exposed to water vapor atmospheres at temperatures ranging from $20^{\circ} \mathrm{C}$ for thousands of years to $230^{\circ} \mathrm{C}$ for days is dominated by molecular water 
diffusion* [1-3]. Because this system is dominated by molecular water diffusion, it allows us to isolate and quantify molecular water diffusion without interference from alkali exchange or etching, an option not possible with basalt glasses. Therefore, while basalt glasses are closer to projected nuclear waste glass compositions than obsidians, the known reaction mechanism for natural obsidian allows the study of long-term water diffusion, isolated from other reaction processes.

The goal of this study is to quantify molecular water diffusion in the natural analogs obsidian and tektites. Results from this study can be used in assessing the importance of factors affecting molecular water diffusion in nuclear waste glasses, relative to other identified reaction processes. In this way, a better understanding of the long-term reaction mechanism can be developed and incorporated into performance assessment models.

\section{EXPERIMENTAL}

We report the resuits of vapor hydration tests for fourteen obsidians and one tektite reacted at 75 to $230^{\circ} \mathrm{C}$ for up to 256 days. The selection criteria for these glasses were based on XRF analyses and a set of scoping experiments. In this way a compositionally diverse suite of glasses known to react via molecular water diffusion were included in the test matrix. Glass monoliths were prepared by initially core-drilling or sawing portions of each obsidian. Each piece was sliced into wafers approximately $1 \mathrm{~cm}$ thick. Two radially opposed notches were made on each monolith to allow each sample to be later suspended in a test vessel. Each face of the sample was polished initially with 600 grit carborundum paper, using water as a lubricant. Diamond pastes of 6 and $1 \mathrm{~mm}$ with oil as a lubricant were used sequentially to obtain the final finish. Between each polishing step the samples were thoroughly rinsed and ultrasonically cleaned in methanol. Glass preparation was generally performed on the same day that experiments were started to minimize the effects of interactions with atmospheric water.

Each sample was suspended by a Teflon® thread from a $304 \mathrm{~L}$ stainless steel support. Samples were arranged so that they contacted neither the vessel walls, the stainless steel support nor other samples. Immediately prior to the initiation of each experiment the suspended samples were thoroughly rinsed a final time in methanol and allowed to air dry. Experiments were performed at $100 \% \mathrm{RH}$ using sealed Parr $\&$ bombs with softened $\mathrm{Cu}$ gaskets. The suspended samples were placed in a vessel and preheated to $200^{\circ} \mathrm{C}$ for approximately two hours. The vessels were then placed in a pan of water and a known volume of distilled water, sufficient to provide a $100 \% \mathrm{RH}$ atmosphere at temperature, was immediately added to the cooled vessel bottom, and the vessel sealed and placed in the reaction oven. This step prevents water from initially condensing preferentially on the glass surface. Experiments were conducted in convection ovens where the temperature was controlled to $\pm 1^{\circ} \mathrm{C}$. Water losses from any of the experiments were negligible and were not believed to have affected these experiments.

At the termination of each experiment, each sample was thin-sectioned and the thickness of the birefringent hydration layer measured, using previously described procedures [7]. An Aus Jena optical microscope with a $40 \mathrm{X}$ objective

"(Note that the same experiments performed in hydrothermal leach tests involve the simultaneous interaction of molecular water diffusion, ion exchange, etching and secondary mineral precipitation [4-6]. 
was used to examine $30 \mu \mathrm{m}$ thick sections of each reacted sample. The hydration layer thicknesses we report are the average of seven measurements on each sample with a variation of $\pm 0.2 \mu \mathrm{m}$. All samples were measured by the same operator so that any systematic operator induced errors would be constant throughout the measurements [8].

\section{RESULTS}

Approximately two hundred experiments were performed and in every case, a birefringent hydration layer was identified. The rate of formation of the birefringent hydration layers was constant as a function of the square root of time, Figure 1 , in excellent agreement with previous reports of obsidian hydration $[1,3,9,10]$. The isothermal rate constants for the different obsidians varied by more than a factor of two. The cause for these disparities was investigated by considering a number of possible compositional factors that may influence the rate of hydration and glass composition. The strongest correlation was with the initial total water content of glass, Figure 2. The temperature dependence of the reaction is characterized by an activation energy that ranged between 75 to $100 \mathrm{~kJ} / \mathrm{mol}$, Figure 3 , and also shows a strong correlation with the initial total water content of glass. These results are described in greater detail elsewhere [3], but their significance is that we are able to quantitatively describe molecular water diffusion in silicate glasses as a function of glass composition and temperature over a range of conditions relevant to the proposed Yucca Mountain repository.

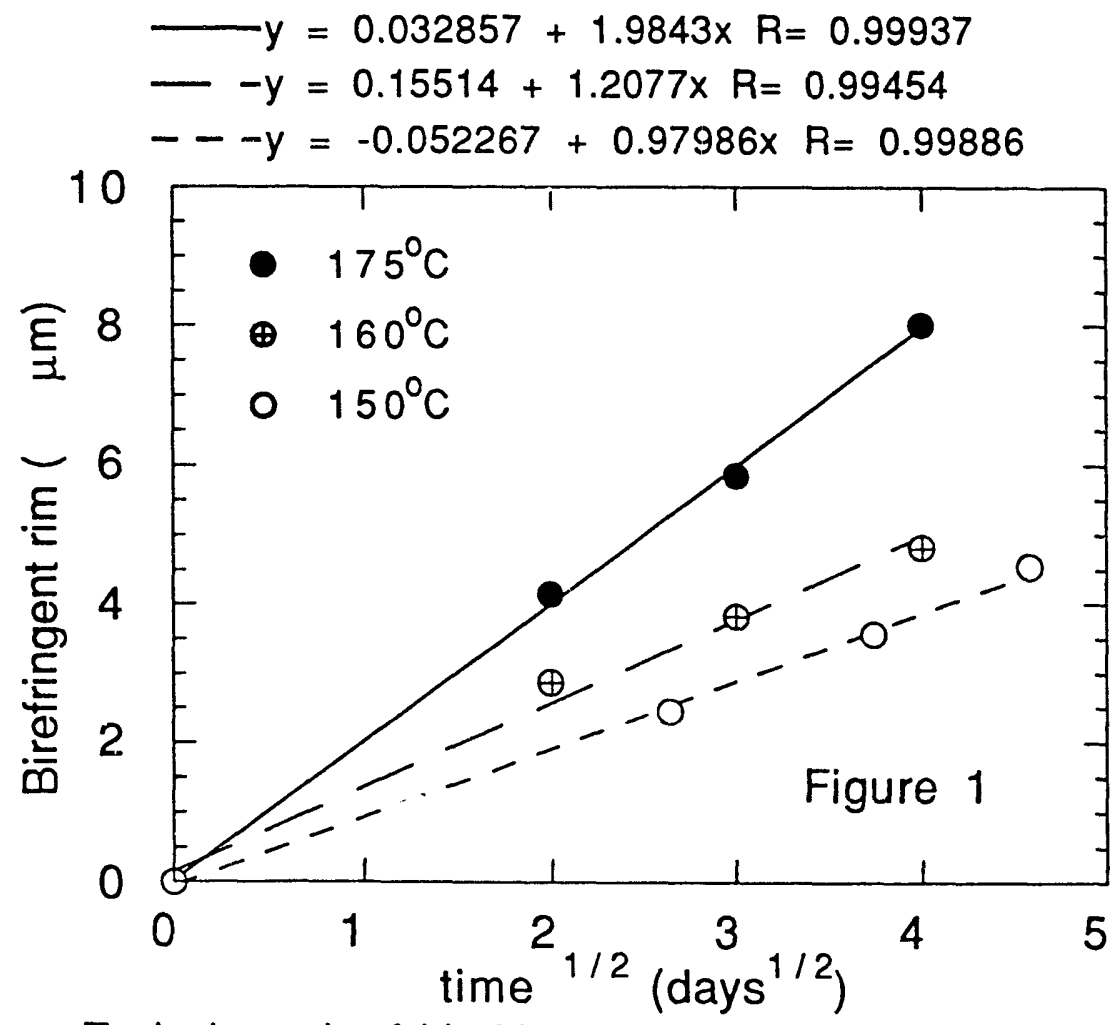

Figure 1. Typical graph of birefringent alteration layer plotted as a function of the square root of time. This particular data set was obtained using Snake River obsidian at 175 (filled symbols), 160 (cross-filled symbols) and $150^{\circ} \mathrm{C}$ (open symbols). In each case the rate of layer formation is linear with the square root of time. Equations are for linear regression fits, with correlation coefficients of $R$. 


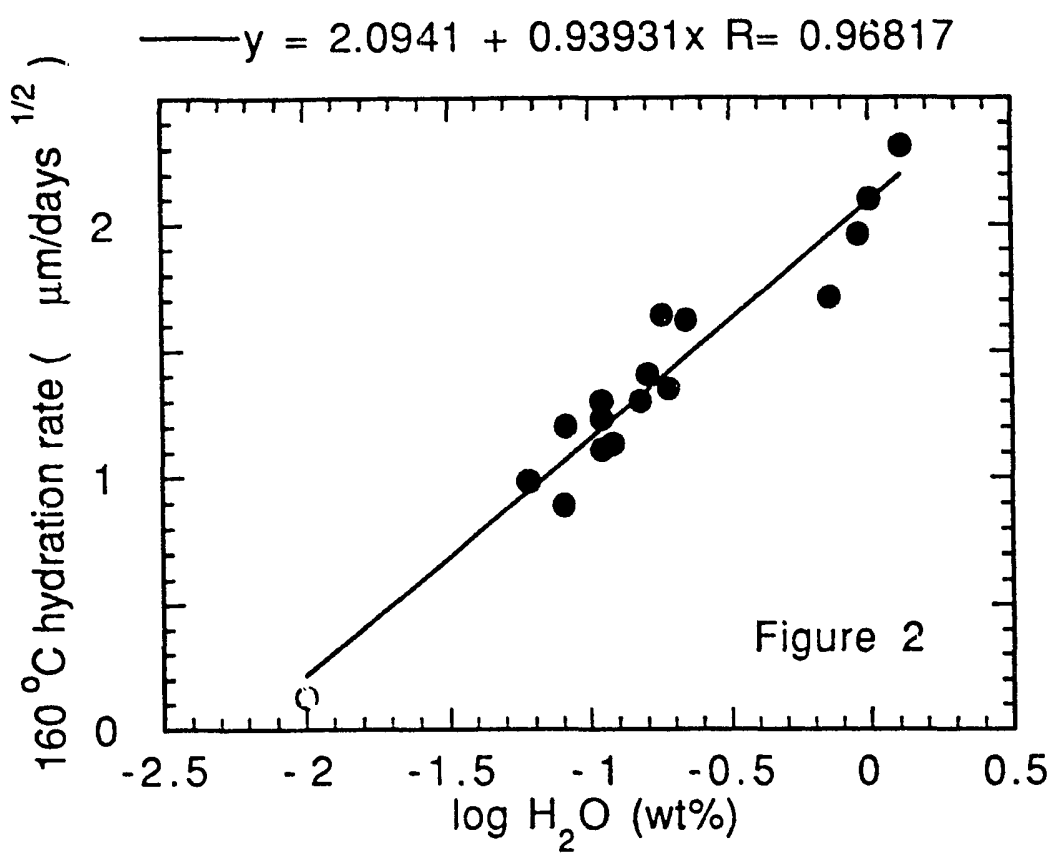

Figure 2. The relationship between the $160^{\circ} \mathrm{C}$ hydration rate $\left(\mu \mathrm{m} /\right.$ days $\left.\mathrm{s}^{1 / 2}\right)$, as determined by the change in thickness of the birefringent alteration layer with time, and the intrinsic water content of obsidians (filled symbols) and tektite (open symbol). The equation is a linear regression fit to the data with a correlation coefficient of R.

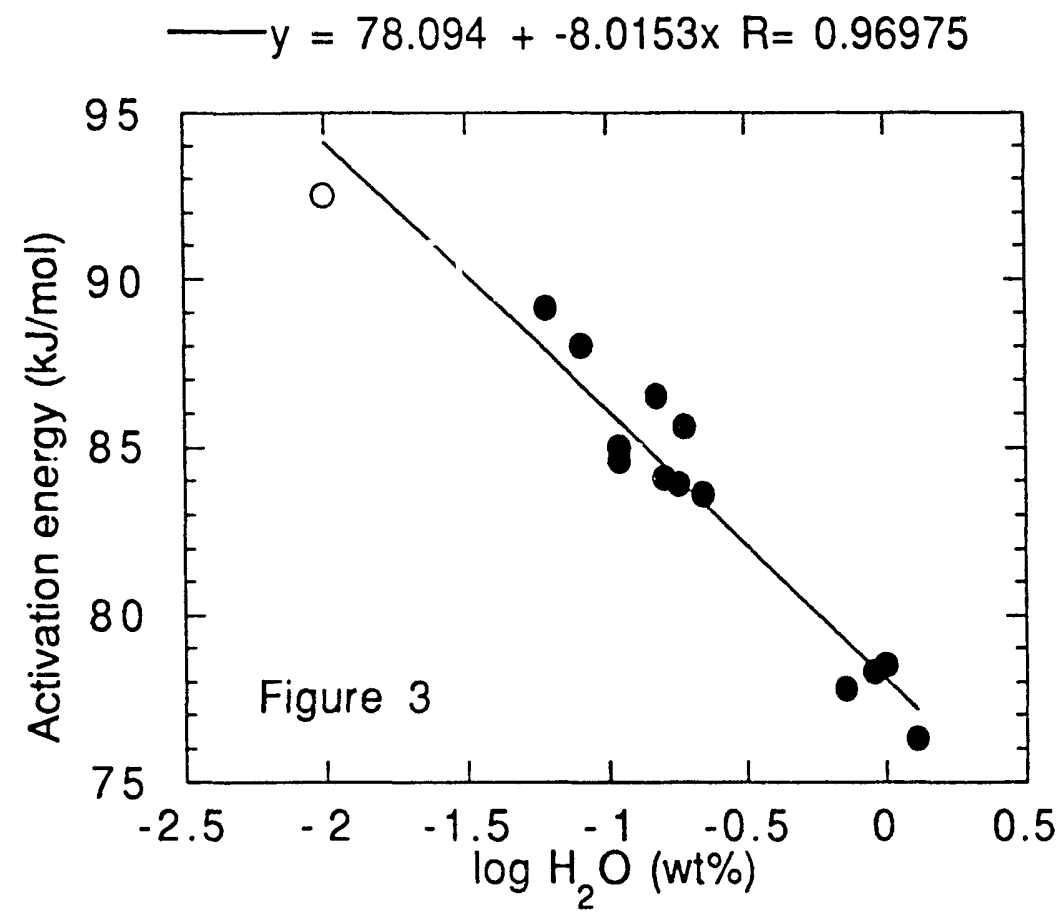

Figure 3. The relationship between the temperature dependence of molecular water diffusion, as measured by the activation energies, in natural glasses and their intrinsic water content for obsidians (filled symbols) and tektite (open symbol). The equation is a linear regression fit to the data with a correlation coefficient of $R$. 
A second natural analog known to react via molecular water diffusion under some conditions are tektites. Tektites, natural glasses believed to have formed from extra-terrestrial impacts, have compositions somewhat similar to obsidians, but have significantly lower intrinsic water contents [11]. The tektite reaction mechanism in hydrothermal solution is thought to be dominated by etching [12,13]. Given the similarities in composition to obsidian, we decided to examine tektite reaction under vapor hydration conditions and see if it is dominated by molecular water diffusion. Tektites can serve as another natural glass analog and are known to have existed for millions of years. Recent studies of the Cretaceous-Tertiary boundary (approximately 56 million years old) have found non-marine occurrences of tektite glass diagenetically transformed to clay phases [14,15]. Results from our experiments on tektite glasses resulted in the formation of birefringent hydration layers and in some cases the initial formation of clay phases, Figure 4 . The results of these analyses indicate that molecular water diffusion is the rate controlling reaction process in these experiments and suggest that our tektite experimental results are consistent with our obsidian results. The results of this analysis are consistent with the intrinsic water content being the most important compositional parameter, with respect to molecular water diffusion at our experimental conditions, cf. Figures 2 and 3 .

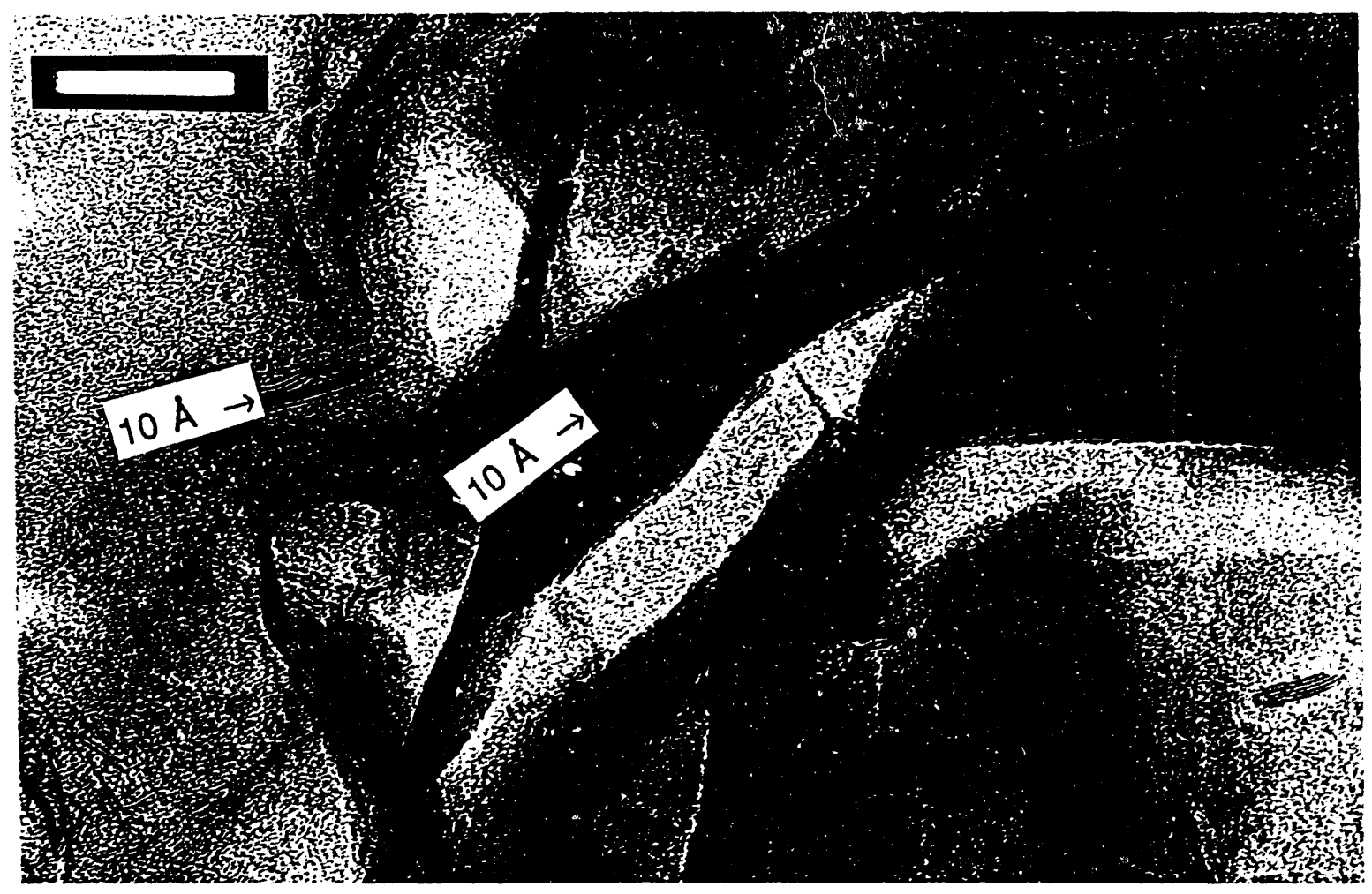

Figure 4. AEM photograph of tektite experimentally altered for 22 days at $200^{\circ} \mathrm{C}$ in $100 \% \mathrm{RH}$ vapor. Infrequent occurrences of $10 \mathrm{~A}$ Fe-rich glauconitic illite mineral was found in the outermost $100 \mathrm{~nm}$ of the surface layer. A 4.3 $\mu \mathrm{m}$ birefringent layer was measured on this sample using optical microscopy. Scale bar represents $0.5 \mu \mathrm{m}$. 
The results of this study has immediate applications for archaeologists and geologists using obsidian hydration dating $[1,16]$ to date obsidian artifacts and natural geologic features that are up to thousands of years old. Quantitative predictioris of obsidian hydration rates can be generated from measurements of the initial total water content of obsidian, removing experimental uncertainty resulting from experimentally determining an obsidian's hydration rate and activation energy.

\section{IMPLICATIONS FOR NUCLEAR WASTE GLASS CORROSION}

Experimentally altering these natural glass analogues allowed us to quantify molecular water diffusion in silicate glasses and these results can be applied to studies of water interactions with nuclear waste glasses. In order to use this analytical approach, it is necessary to fully characterize the nuclear waste glass reaction mechanism, a task that has not been completed for most waste glass compositions. Specifically, the question of whether the effects of molecular water diffusion are overwhelmed by the effects of competing reaction processes must be answered for the short-term and long-term reactions.

Measurements of the initial total water content of Savannah River Lab (SRL) nuclear waste glasses produced at the bench-top scale are reported to be on the order of 0.05 to $0.1 \mathrm{wt} \%$ [17]. If similar low water concentrations are found in glasses produced in the full-scale DWPF, then the effects of molecular water diffusion in waste glasses will be minimized. The results from Figures 2 and 3 indicate that at $90^{\circ} \mathrm{C}$ the rate of water diffusion will range from 0.08 to $0.11 \mu \mathrm{m} /$ days $\mathrm{s}^{1 / 2}$ in $\mathrm{SRL}$ glasses. This is slower than the overall rate of short-term glass reaction [17], indicating that water diffusion is not initially rate-controlling. Since the reaction mechanism may change for the long-term reaction (i.e., clay phases begin to form on tektites) it is unknown if water diffusion becomes important for long-term waste glass reaction.

Since the reaction mechanism in SRL waste glasses is much more complicated than that found in obsidian or tektite glasses [17] the results of the present study are applied by assessing how water diffusion may become important. The identification of initial total water content of glasses and its effect on subsequent molecular water diffusion in natural analogs can be useful in helping to understand the effects of this process in models of nuclear waste glass reaction mechanisms.

\section{CONCLUSIONS}

The laboratory reaction of water with obsidian and tektite glasses in water saturated atmospheres produces birefringent alteration layers that for as a function of the square root of time, in agreement with previous studies. A strong correlation exists between the total water content of obsidian and the hydration rate and the activation energy of the reaction. We are able to quantify the correlation so that $160^{\circ} \mathrm{C}$ rate $\left(\mu \mathrm{m} /\right.$ days $\left.^{1 / 2}\right)=0.94\left[\log \mathrm{H}_{2} \mathrm{O} w t \%\right]+2.09$ and $E_{\text {act }}(\mathrm{kJ} / \mathrm{mol})=-8.02$ [log $\left.\mathrm{H}_{2} \mathrm{O} w t \%\right]+78.1$. These correlations can also be applied to tektite glasses, which are somewhat compositionally diverse from obsidians. Understanding the effects and magnitude of molecular water diffusion can help elucidate the reaction mechanisms responsible for forming the complex alteration assemblages observed on hydrated nuclear waste glasses and help project the long-term performance of glass in a repository. 


\section{ACKNOWLEDGMENTS}

Work supported by the U.S. Department of Energy, Office of Environmental Restoration and Waste Management, under Contract W-31-109-ENG-38.

\section{REFERENCES}

1. FRIEDMAN I. and LONG W. D. (1976) Hydration rate of obsidian. Science 191, 347-352.

2. LEE R. R., LEICH D. A., TOMBRELLO T. A., ERICSON J. E. and FRIEDMAN I. (1974) Obsidian hydration profile measurements using a nuclear reaction technique. Nature 250, 44-47.

3. MAZER J. J., STEVENSON C. M., BATES J. K. and BRADLEY J. P., The effect of glass composition on the experimental hydration of obsidian between 110 and $230^{\circ} \mathrm{C}$. submitted to Chemical Geology.

4. YANG W. H. and KIRKPATRICK R. J. (1990) Hydrothermal reaction of rhyoliticcomposition glass: A solid state NMR study. Amer. Min. 75, 1009-1019.

5. LANFORD W. A., BURMAN C., DOREMUS R. H., MEHROTRA Y., and WASSICK T. (1983) Nuclear reaction analysis of glass surfaces: The study of the reaction between water and glass. in Advances in Mater. Char., p. 549

6. WHITE A. F. and CLAASSEN H. C. (1980) Kinetic model for the dissolution of a rhyolitic glass. Chem. Geol. 28, 91-109.

7. STEVENSCN C. M., FREEBORN W., and SCHEETZ B. E. (1987) Obsidian hydration dating: an improved optical technique for measuring the width of the hydration rim. Archaeometry 29, 120-123.

8. STEVENSON C. M., CARPENTER J. and SCHEETZ B. E. (1989) Obsidian dating: recent advances in the experimental determination and application of hydration rates. Archaeometry 31, 193-206.

9. MICHELS J. W., TSONG I. S. T. and SMITH G. A. (1983) Experimentally derived hydration rates in obsidian dating. Archaeometry 25, 107-117.

10. STEVENSON C. M., DINSMORE D., and SCHEETZ B. E. (1989) An interlaboratory comparison of hydration rim measurements. International Association for Obsidian Studies Newsletter. v.1, 7-14.

11. O' KEEFE J. (1984) Natural Glass. J. of Non-Cry'stalline Solids, 67, 1-17.

12. LaMARCHE, P. H., RAUCH F. and LANFORD W. A. (1984) Reaction between water and tektite glass. Journal of Non-Cryst. Solids, 67, 361-369.

13. BARKATT A. A., BOULOS M. S., BARKATT A., SOUSANPOUR W., BOROOMAND M. A., MACEDO P. B. and O'KEEFE J. A. (1984) The chemical durability of tektites- A laboratory study and correlation with long-term corrosion behavior. Geochim. Cosmochim. Acta 48, 361-371.

14. SIGURDSSON H., D'HONDT S., ARTHUR M. A., BRALOWER T. J., ZACHOS J.C., VAN FOSSEN M., and CHANNELL J. E. T. (1991) Glass from the Cretaceous/Tertiary boundary in Haiti. Nature 349, 482-487.

15. MONTANARI A., HAY R. L., ALVAREZ W., ASARO F., MICHEL H. V., ALVAREZ L. W. and SMIT J. (1983) Spheroids at the K-T boundary are altered impact droplets of basaltic composition. Geology 11, 668-671.

16. FRIEDMAN I. and OBRADOVICH J. (1981) Obsidian Hydration dating of volcanic events. Quaternary Research 16(1), 37-41.

17. BATES J. K. (1991) Personal communication. 

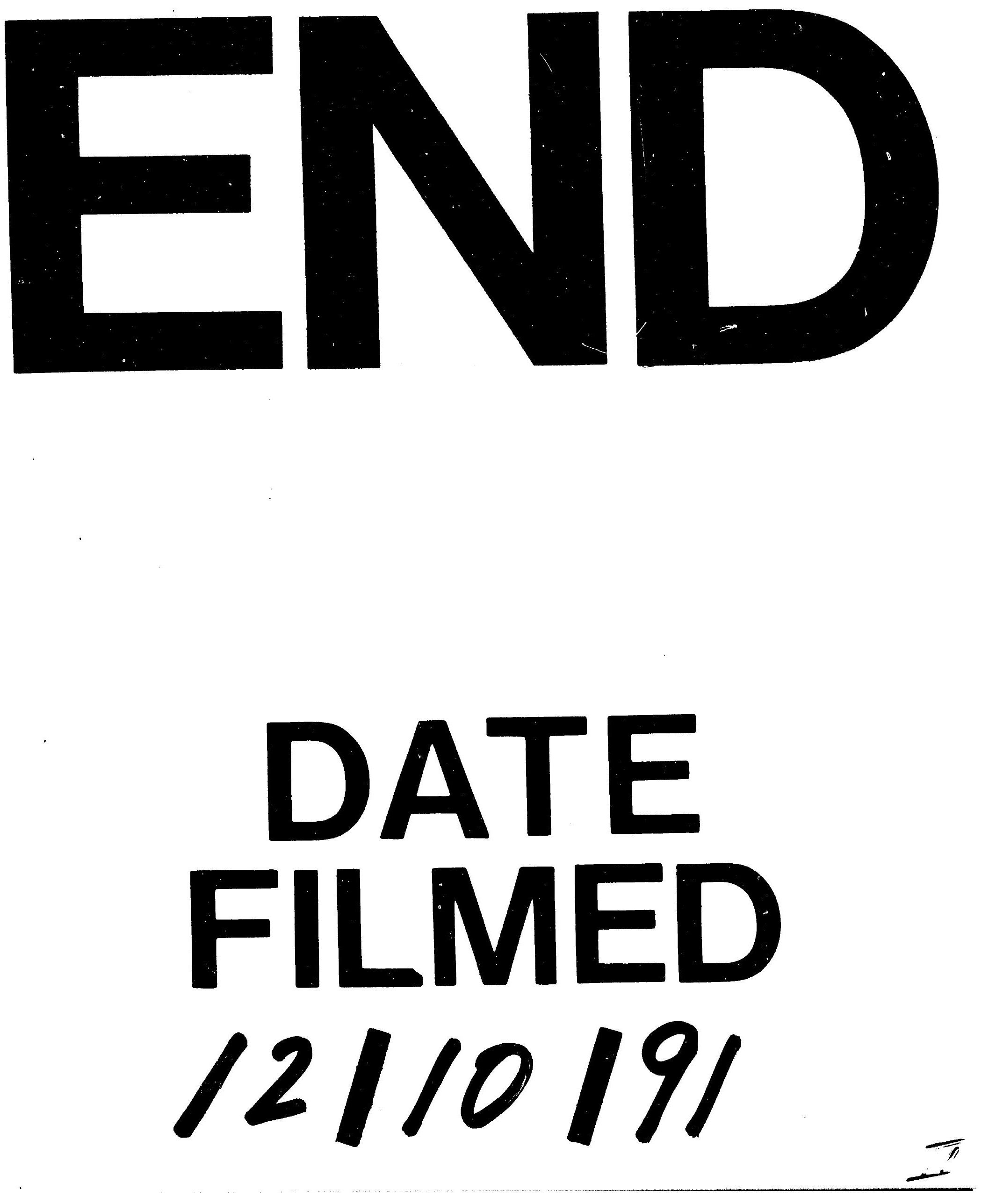
